\title{
EducaÇão especial e EdUCAÇÃo INCLUSIVA: desafios PARA a CONS- TRUÇÃO DO DIREITO À EDUCAÇÃO
}

\author{
Wanda Maria Braga BARROS
}

LIMA, Priscila Augusta. Educação inclusiva e igual dade social. São Paulo: A vercamp, 2006.

Priscila A ugusta Lima é psi cóloga formada pela Universidade Federal de M inas Gerais e professora-adjunta de Psicologia da Educação e Fundamentos da Educação Inclusiva e Educação Especial nos cursos de Licenciatura e Pedagogia da Faculdade de Educação da UFMG. A tuando como docente na área, relata que, em sua trajetória profissional, teve dificuldade de encontrar as temáticas sobre Educação Inclusiva e Educação Especial relacionadas em um único texto. Com intuito de superar essa lacuna, a intenção da autora nesta obra é oferecer uma concepção do processo de inclusão e ao mesmo tempo, trazer informações abrangentes sobre educação especial com enfoque na inserção de alunos com necessidades educacionais especiais nas salas comuns da rede regular de ensino.

As reflexões contidas no livro foram construídas a partir das diversas experiências da autora, vivenciadas com pessoas com necessidades especiais e da sua experiência profissional, especialmente como consultora nas atividades de assessoria às escolas no processo de inclusão.

A autora inicia o capítulo 1 contextualizando o movimento de inclusão para relatar em que circunstâncias aconteceram o seu primeiro contato e o trabalho desenvolvido com pessoas com deficiência. Numa perspectiva dialética, discute a inclusão na sociedadecapital ista partindo de doisprincípios contraditórios: aigualdade e a diversidade. Ainda nesse capítulo, analisa os conceitos de integração e indusão, terminol ogias encontradas em muitos textos na área, mas com diferentes acepções.

Valendo-se da abordagem histórica, no capítulo 2, Lima defineeducação inclusiva e educação especial. Ressal ta o impacto dos movimentos sociais que confluíram em políticas educacionais que visam a Educação como um direito de todos os cidadãos. A presenta as maneiras distintas pelas quais os educadores e a sociedade apropriaram-se do debate sobre inclusão no Brasil. Conclui o capítulo, fazendo um balanço do processo de inclusão em nosso país.

O capítulo seguinte- intitulado "N ecessidades Educacionais Especiais: Distinções e Incidências" - inicia-se com a autora estabelecendo relação entre condição social e deficiência para, em seguida, distinguir conceitualmente deficiência de incapacidade. Utiliza, para tanto, dados estatísticos oficiais sobrea inci dência das deficiências na população ea escolaridade dessas pessoas no ensino

${ }^{1}$ Mestranda do Programa de Pós-graduação em Educação da Pontifícia Universidade Católica de Campinas wandambb@hotmail.com 
regular eespecial, deixando evidentequeainda estamos longe de efetivar a inclusão das pessoas com necessidades educacionais nos diversos níveis de ensino.

Surdez, deficiência visual e deficiência mental e altas habilidades congregam os capítulos 4, 5e6, respectivamente. Estes capítulos trazem informações relevantes sobre conceito, etiologia (causa da deficiência), pressupostos para o ensino-aprendizagem e possibilidades perceptivas. Para desenvolvêlos, Lima apóia-se em teóricos como Vygotsky, Piaget e Luria; também faz referências às análises do neurologista britânico, Sacks. Na categoria da surdez, embasa-se em pesquisadores da área, como Vieira, Ferrari, Marchesi, Couto-Lenzi, Góes, Costa, dentreoutros; para abordar a deficiência visual, a autora contribui com os resultados da sua tese de doutorado e os estudos de Jose, Rocha, Masini, Lima, Millar, Rosa e Ochiata; para discutir deficiência mental ealtas habilidades, problematiza o conceito de inteligência fundamentando-se em Vygotsky e Piaget.

Os exemplos apresentados, principalmente das pesquisas empíricas, ajudam a entender o universo das pessoas com deficiência; apontam para questões importantes como a comuni cação e a construção da linguagem para a pessoa surda e a importância do domínio da movimentação espacial para a pessoa cega.

No próximo capítulo, quevai discutir arelação entrepobreza edeficiência, aautora afirma que: “a maioria dassituações deexclusão está associada a uma pobreza extrema" (p.114). Além disso, demonstra quea deficiência atribuída à criança pobreé resultado de uma construção social e educacional, ao invés de uma real deficiência.

A formação de professores e pesquisadores para educação inclusiva é assunto polêmi co e muito bem problematizado no capítulo 8. Lima enfatiza que o ponto de partida para a inclusão escolar é a formação humana dos educadores seguida da formação técnica associada à interação com as pessoas com deficiência. Assim, "informação, a formação de basee o conhecimento especializado constituem uma vertente significativa - e é neste sentido que se busca consolidar esta obra" (p.123), ressalta a autora.

O capítulo 9 apresenta al guns cami nhos metodológicos para pesquisa sobre pessoas com necessidades educacionais especiais e as possibilidades de trabal ho com elas. A autora faz uma preleção sobre a importância do lúdico como atividade simbólica ou cognitiva no trabalho com a pessoa com deficiência.

Merecem destaqueos anexos quevão subsidiar as pessoas interessadas na área. N eles encontram-se si nopses de filmes sobre a temática das necessidades especiais, algumas legislações e diretrizes pertinentes ao campo da educação inclusiva. Por fim, ainda nos anexos, são relacionados "sites" especializados na temática, apresentados como sugestão.

Com uma linguagem acessível, a Profạ Priscila Augusta Lima consegue levantar nestelivro, em linhas gerais, as principais questões sobre educação indusiva e educação especial. Traz informações que serão úteis e servirão como ponto de partida, não somente aos professores eestudantes da área, mas a todos que queiram compreender eatuar no campo da educação inclusiva e educação especial. 